\title{
ICT: A Cornerstone for Effective Weather Forecasting
}

\author{
Onu Fergus U. \\ Department of Computer Science, Ebonyi \\ State University, \\ Abakaliki-Nigeria
}

\author{
Nwagbo Chioma L. \\ Department of Computer Science, \\ Nwafor Orizu College of Education, \\ Nsugbe-Nigeria
}

\begin{abstract}
Weather conditions continue to change at uncontrolable rate. The continous change bring about unberable hazard which needs high precision tools for its control. The global community have understood that the potential magnitude, harshness and impact of the symptoms of weather changes such as: global warming, loss of crops through over extensive periods of drought, unpredictable rainfall patterns, melting glaciers, displaced populations in search of refuge after floods, or entire villages devastated by the cruel force of cyclones and hurricanes on upcoming generations will be very intense. It is therefore assumed that information and communication technology is a key technology tools which can be used to ease, adapt to and monitor Weather condition. This paper therefore examines the linkage between Information and Communications Technologies (ICTs) and Weather Forecasting; it also looked into the signs and effects of Weather condition and the ICT solutions. It was deduced that ICTs not only help in advanced weather forecasting and climate monitoring, but are very essential in information circulation to a large audience through mobile devices. Finally, this paper, recommends solutions on how proposed information and communication technology strategies can be adopted to alleviate, adapt to and monitor weather condition.
\end{abstract}

Keywords: ICT, Weather forecasting, Mitigating Weather change, monitoring Weather condition, adapting to Weather condition, role of ICT in Weather forecasting, 


\section{INTRODUCTION}

The world today is constantly experiencing changes in weather conditions, which its negative impacts include: global warming, floods, droughts, heat waves, etc. These harsh weather conditions affect both developing and developed countries although the poor/developing countries are most hit. [1] asserts that "Africa is hardest hit due to it's rich industrialized countries in the North that are responsible for 75 percent of green house gas emissions. Zimbabwe is suffering more in Africa, showing the effect of weather change risks which is felt more by the poor now and in the near future." Furthermore, some nations who do not contribute negatively to weather change and others whose contributions to weather change are minimal are also being affected by the negative consequences of weather change are frequently and greatly affected more than the real culprits.

It is a sad fact that more people are dying now than ever before and more diseases are surfacing as a result of weather change and more property is being destroyed now than ever before due to weather conditions. Weather change has and continues to be a major economic setback for most people especially in developing countries. The Fourth Assessment Report of the Inter-governmental Panel on Climate Change indicated that Africa will suffer the most from the impacts of climate change.

Forecasting is used to analyze long/short and isolated series of weather problems, whose data are often collected via files, input/sensing devices and processed or run using Hybrid computers.

When numerous items such as weather condition must be forecasted on a frequent regular basis, the uses of pre-defined or automatic forecasting techniques are critical. Weather forecasting systems must not only meet global information reports for accuracy but also for processing speed and robustness in adapting to and monitor Weather conditions. [2]
Weather Forecasting is therefore the prediction of change in weather condition to determine the signs, possible impact, location and effects of Weather change. These forecast of weather changes are achieved through Information and Communication Technologies (ICT) which is a key technology for weather forecasting. ICTs not only help in advanced weather forecasting and climate monitoring, but are very essential in information circulating to large global audiences. It can help address major adaptation risks such as food and water shortages through providing early warning systems and better monitoring of soil conditions and water quality.

\section{THE OBJECTIVE OF THE STUDY IS TO:}

Determine the link between ICT and weather forecasting.

Explain the use of ICTs information dispersal to people who could be affected in order to adapt to the effects of weather change.

Document signs and effects of weather change.

Articulate the causes of weather change.

Establish the role of ICTs in adapting to weather change.

Determine the role of ICTs in mitigating weather change.

Reduction of high risk in weather changes through Risk analysis.

\subsection{Use Of Icts For The Dispersal Of Weather Change Information}

From 1980-2005, over 7,000 natural disasters happened worldwide in which millions of lives were lost. Ninety percent of these disasters were caused by weather and water connected events such as floods, cyclones and droughts [3]. on the other hand, we will show how the science of 
weather forecasting and weather monitoring, which is serious to reducing such high casualty rates, is being advanced by the development in ICTs.

The Nairobi Framework[16], adopted in 2006, aims to assist all United Nations Framework Convention on Climate Change (UNFCCC) reporting Parties, in meticulous developing countries, including the Least Developed Countries (LDCs) and Small Island Developing States (SIDS), to pick up their understanding and assessment of impacts, openness and adaptation, and to make informed result on practical adaptation actions and measures to respond to weather change on a sound scientific, technical and socioeconomic basis, taking into report current and future change in weather condition and variability. As part of its commitment to contribute to the battle against weather change, the International Telecommunication Union (ITU) is a partner of the Nairobi Framework programme.

The ITU is the particular agency of the United Nations responsible for information and communications technologies (ICTs). Its membership, comprising 192 governments and over 700 private companies, has called for the ITU to take the lead in appealing the global community (including the UN system and the ICT industry, as well as academia and NGOs) to address weather change through the use of ICTs.[4],[5].

\subsection{Signs and Effects Of Weather Change}

Weather change can have serious developmental effects that hit particularly hard those countries that are already experiencing the hardships of poverty and marginalization. From the foregoing statement, it is crystal clear that weather change has developmental effects especially on poor developing nations. Regarding the main characteristics of weather change, the United Nations Framework Convention on Climate Change [6] , increases in average global temperature (global warming); changes in cloud cover and precipitation particularly over land; melting of ice caps and glaciers and reduced snow cover; and increases in ocean temperatures and ocean acidity - due to seawater absorbing heat and carbon dioxide from the atmosphere. Global warming has changed the type, frequency and intensity of extreme events, such as heat waves, tropical cyclones (including hurricanes and typhoons), floods, droughts and heavy precipitation.

UNFCCC establishes that Africa is already a continent under pressure from climate stresses and is highly vulnerable to the impacts of climate change. They noted famine and widespread disruption of socio-economic wellbeing as some of these impacts in Africa [2].

Migration of the malaria mosquito to higher altitudes will expose large numbers of previously unexposed people to infection in the densely populated east African highlands. Weather change is an added stress to already threatened habitats, ecosystems and species in Africa, and is likely to trigger species migration and lead to habitat reduction.

Report from the investigate carried out in Zimbabwe on effects of weather change on agriculture[7]. In their study, it was found out that weather change negatively affects maize production and some areas in Zimbabwe might be turned into non-maize producing as a result of drought. Further to that, Zimbabwe's Initial National Communication under the United Nations Framework Convention on Climate/weather Change indicates that weather change has adverse effects on human health for instance, in Zimbabwe; the incidence of malaria was very high after heavy rains and high temperatures throughout the country. Due to weather change, Zimbabwe is experiencing an increase in the frequency of floods.[8],[9].

Looking at the African continent the main impact of weather/ climate change on the continent will be increased frequency of natural disasters, droughts, floods and other weather extremes that lead to loss of life, economic 
disruptions, social unrest and forced migration as well as major environmental problems.[10] Russell went on to say "prolonged drought periods will cause stress on water resources and reduce food security due to diminished agricultural productivity, increase outbreaks of vector borne diseases and other health impacts.

All the above cases of the effects and signs of weather change point to the fact that developing countries are experiencing the negative impacts of weather change. This problem is not affecting only developing countries but all countries in the world. Weather change is a global problem which requires collective solutions and collective effort from all countries [9].

\subsection{Causes Of Weather Change}

There are two classes of causes of climate change namely natural causes and man-made causes. International Telecommunication Union (ITU) went to say that natural causes include variations in solar radiation, volcanic activity and so on[5]. They Further, asserts that manmade weather change is of major concern because it appears to be leading to a progressive and accelerating warming of the planet, as a result of the release of greenhouse gases (GHG), primarily carbon-based emissions. On the other hand, the United Nations Framework Convention on Climate Change names two major causes of weather change which are rising fossil fuel burning and land use changes. The United Nations Framework Convention on Climate Change notes that these two activities have emitted, and are continuing to emit, increasing quantities of greenhouse gases (such as carbon dioxide, methane, and nitrogen dioxide) into the Earth's atmosphere. A rise in these gases has caused a rise in the amount of heat from the sun withheld in the Earth's atmosphere, heat that would normally be radiated back into space. This increase in heat has led to the greenhouse effect, resulting in weather/climate change [11],[12].

it is clear that human activity is the major contributor to weather change.

\subsection{The Role of ICTs In Adapting To Weather Change.}

Some adaptation strategies have been proposed in earlier researches such as Zimbabwe's Initial National Communication under the United Nations Framework Convention on Climate Change [7] ,[13]. However, the strategies proposed in the context of a developing country

Wireless communications and Early Warning Systems are adopted to facilitate efficient disaster warning and emergency response. Global e-Sustainability Initiative proposes solutions which are not very much special from the above solutions. Some of the examples of ICT solutions for adaptation proposed by Global e-Sustainability Initiative consist of, early warning systems where ICT systems are used to provide people with warnings and information regarding threats like extreme weather events, smart planning in which ICT systems are used to improve urban and rural planning and solutions can be tested based upon their resilience, e-health where smart ICT can bring down costs for health and permit correct treatment, especially in case of pandemics and new health challenges where local knowledge might be lacking and lastly education where ICT can help reduce costs, enable access and develop the quality of education through telecentre, use of e-learning systems.[14],[15].

IPCC report on weather change tackles the priorities of developing countries through adaptation (i.e. recovery and adjustment in the face of change in weather conduction)[11]. IPCC further asserts that the potential of ICTs in adapting to weather change is now evident in use of devices like mobile phones and other applications used in adapting to climate change[11] investigate.

\subsection{The Role of ICTs In Mitigating Weather Changes}

Information and communication technologies (including radio and telecommunication technologies, standards and supporting 
publications) are being used for weather forecasting, climate monitoring, predicting, detecting and mitigating the effects of natural disasters. [12]ITU cites technologies which allow remote monitoring and data collection using ICT-equipped sensors (telemetry). In addition to that, they also cites aerial photography, satellite imagery, grid technology and in particular the use of global positioning by satellite (GPS) for tracking slow, long-term movement, for instance of glaciers or ice floes.[2].

Satellites and weather radars also track the advancement of hurricanes and typhoons and tracking tornadoes, thunderstorms, and the effluent from volcanoes and major forest fires. Also, the radio-based meteorological aid systems accumulate and process weather data. It is further asserted that distant from monitoring the effects of climate change, ICTs have as well proved invaluable in computer modeling of the earth's atmosphere [12].

Further to that supercomputers are being used in meteorological services to produce complex general circulation models of weather. Further, different radio-communication systems (satellite and terrestrial) are used for dissemination of information concerning diverse natural and man-made disasters [12].

In addition to the foregoing solutions, ITU indicates that the role of ICTs in weather /climate monitoring is shown in the structure of the World Meteorological Organization's (WMO) World Weather Watch (WWW), which involves three integrated core system components as follows:

- $\quad$ The Global Observing System (GOS) that provides observations of the atmosphere and the Earth's surface (including oceans) from the globe and from outer space. The GOS uses remote sensing equipment placed on satellites, aircraft, radios and relay data to environment control centers.

- The Global Telecommunication System (GTS) - radio and telecommunication networks for realtime exchange of a huge volume of data between meteorological centers. The Global Data Processing System (GDPS) - thousands of linked mini, micro and supercomputers, processes an enormous number of meteorological data and generates warnings and forecasts. [7], [10].

From the above discussion, it is clear that ICTs play a major role in monitoring weather change through helping with data collection, dissemination, storage, collaboration, processing and management.

\subsection{Risk Analysis}

ICT as well as remote sensing and geographic information systems have extended the possibilities for risk assessment of multiple hazards and enabled the development of different scenarios and contingency plans. Risk analysis includes: risk maps, hazard maps, and scenario maps. Risk analysis is as a result a key component in developing a disaster risk reduction strategy by establishing the links between exposure to hazards, level of vulnerabilities and the capacity to cope [9]. We all know that information and communications technologies (ICTs) have revolutionized our world...ICTs are also very important to confronting the troubles we face as a planet: the threat of climate change...Indeed ICTs are element of the solution. Already these technologies are being used to cut emissions and help countries adapt to the effects of climate change...Governments and industries that embrace a tactic of green growth will be environmental champions and economic leaders in the twenty-first century.[16],[17].

The impact of global warming on the world's weather condition to date is fairly small evaluated with what can be expected in the future, even if the raise in greenhouse gas emissions is stabilized. moreover, the results are likely to be highly irregular in their distribution, with low-lying coastal areas (such as little island developing States, the Bangladesh delta 
and the Netherlands) at risk because of rising sea levels; sub-Saharan Africa at risk because of desertification; a growing number of environmental refugees; and improved pressure on sources of fresh water and on vulnerable ecosystems such as coral reefs, tundra and coastal wetlands.[16],[18].

\subsection{Link Between ICT and Weather Forecasting}

Weather change endangers the quality and availability of human resources. Adequate weather forecasting information can be passed through radio Broadcast or TV networks supplemented by text messages to offer alerts to the communities at risk, but access to the internet is needed to provide reference information, datasets and adaptation plans. wireless phone networks with internet browsing capability are being extended to bring adaptation forecasting information to remote communities.

Monitoring environmental and soil conditions using ICTs makes farming more profitable and sustainable. Better water management[18] using ICTs improves the overall effectiveness of water use, providing significant savings and a more sustainable use of water resources [14] The foremost areas where ICT could play a pivotal role in water management and weather forecasting are show below: See figure 1.

\section{METHODOLOGY}

\subsection{Using Telecommunication Network For Weather Forecasting.}

Extensive weather station networks are desired for monitoring key weather parameters such as wind speed, precipitation, barometric pressure, soil moisture, wind direction, air temperature and relative humidity. These parameters may be used together for forecasting and for weather modeling. The technologies needed comprise weather satellites and both local and remote automated weather stations. Just as with telecommunications networks in general, there are logistical and financial problems in achieving satisfactory global coverage to collect the required data.[14]

For Satellite observation, visible spectrum cameras are used to detect storms and deforestation. Infrared cameras are for discovering cloud and surface temperatures, sea level rise and particle detectors of solar emissions. The Geostationary Operational Environmental Satellites [4][12], and others, are able of making these observations, which are essential in providing input to weather forecasting and weather change models. Emphasis is on improving coverage of space and land based sensors. Fine resolutions are needed, with regular updates, to provide the most accurate forecasts. For instance the European Meteosat-8 located over the Atlantic Ocean at 0 o longitude provides an operational European 'rapid scan' mode service, which initiated in the second quarter of 2008 (with images of Europe every 5 minutes)[13]. Meteosat-9 also at 0o offers the main full earth imagery service over Europe and Africa (with images every 15-minutes). More work is needed to set up whether Africa and other developing regions could benefit from dedicated weather satellites, with enhanced resolution over their regions, to match the standards of weather change forecasting in developed regions[12].

Weather forecasting information are Broadcasted through wireless phone networks ,bringing solution to the problems of providing sufficient mobile base station coverage and land based weather stations[15] Up to 5,000 automatic weather stations are needed to be installed at cellular sites across Africa. This will increase broadcasting of weather information via wireless phones to users and communities, including remote farmers and fishermen.

Supercomputers are being used for weather Forecasting, for accuracy in weather (general circulation) modeling, is being continuously improved through better understanding of the 
basic science (including the impacts of clouds). For instance, advances in the technology, as observed by Moore's law, whereby the processing power of computers adds every two years, and more data gathering through weather and environmental sensors connected to telecommunication networks. In order to make appropriate information available to local communities these models are being extended to predict changes in regional and local weather and sea level extremes.[14].

\section{DISCUSSION}

This work discussed the major causes of weather change, signs of weather change and its effects. The function of information and communication technologies in mitigating, adapting to and monitoring weather change was also discussed. From the above review the major contributor to weather change is human activity notably the emission of green house gases into the atmosphere. Therefore ICTs have huge potential to mitigate, adapt to and monitor weather change in developing countries despite the fact that these countries are facing a lot of challenges that are making it difficult to apply some of the proposed solutions.

\section{CONCLUSION}

This paper examined the linkage between ICTs and Weather Forecasting, the signs and effects of weather condition and the ICT solutions. The role of information and communication technologies in mitigating, adapting to and monitoring weather change was also discussed.

From the above discussion it is clear that the major contributor to weather change is human activity: the emission of green house gases into the atmosphere.[2].

The paper reached the conclusion that ICTs is a corner stone which have huge potential to mitigate, adapt to and monitor weather change in developing countries even though these countries are facing a lot of challenges that are making it difficult to implement some of the proposed solutions.

In the area of weather change adaptation, ICT based strategies include,

i) Infrastructure innovation which is aimed at reducing energy consumption and

Green House gases (GHGs),

ii) behavioral change and green enablement which focuses on need for global measurement and tracking of carbon reduction, as well as tools that impact positive behavioral change including software tools for measuring carbon footprint, and the use of innovative technologies and opportunities that reduce travel and transportation and

iii) Energy efficiency of data centers, electronic devices and solutions. As regards to weather change monitoring, ICTs can be used for weather forecasting, weather monitoring, predicting, detecting and mitigating the effects of natural disasters. Some of the ICTs that can be used in this area include

iv) The Global Observing System (GOS) which provides observations of the atmosphere and the

Earth's surface (including oceans) from the globe and from outer space,

v) The Global Telecommunication System (GTS) which are radio and telecommunication networks for real-time exchange of a huge volume of data between meteorological centers and

vi) The Global Data Processing System (GDPS) where many networked mini, micro and supercomputers, processes an massive volume of meteorological data and generates warnings and forecasts.

\section{RECOMMENDATIONS}

Weather change is global problem which implies that global solution which is based on use of ICT is required via: 


\section{Volume 6-Issue 3, 121-129, 2017, ISSN:-2319-8656}

Addressing Weather problems at national level by each and every country through creating a budget for weather change. Developing countries that do not have the needed ICT infrastructure can improve through the use of the money each country budget's for weather change. On setting up the infrastructure, it is recommended that each government must use green technologies only.

Mitigating weather change, all involved in the ICT sector, the education sector and the media must take an active role in disseminating information not only about the role of ICTs in mitigating weather change but also about the need for every person to reduce emissions of GHGs into the atmosphere.

Educational administrators and institutions must include weather change in their curriculum from the lowest level possible to the highest level.

Further, the ICT sector should develop affordable software tools that can measure the carbon foot print since it is expensive to import software which was developed elsewhere.

- All private and public owned companies should have software tools which measure its carbon foot print. This is very important because it is difficult to reduce the $\mathrm{CO} 2$ emissions if we cannot measure the carbon footprint,

\section{REFERENCE}

[ 1] Hartványi, T., Nagy 2009." In-sourcing Model for Food Storage and Forwarding." Acta Technica Jaurinensis, Series Logistica. Vol. 2. No. 3.

[2] Zanamwe and Okunoye 2013." Role of information and communication technologies (ICTs) in mitigating, adapting to and monitoring climate

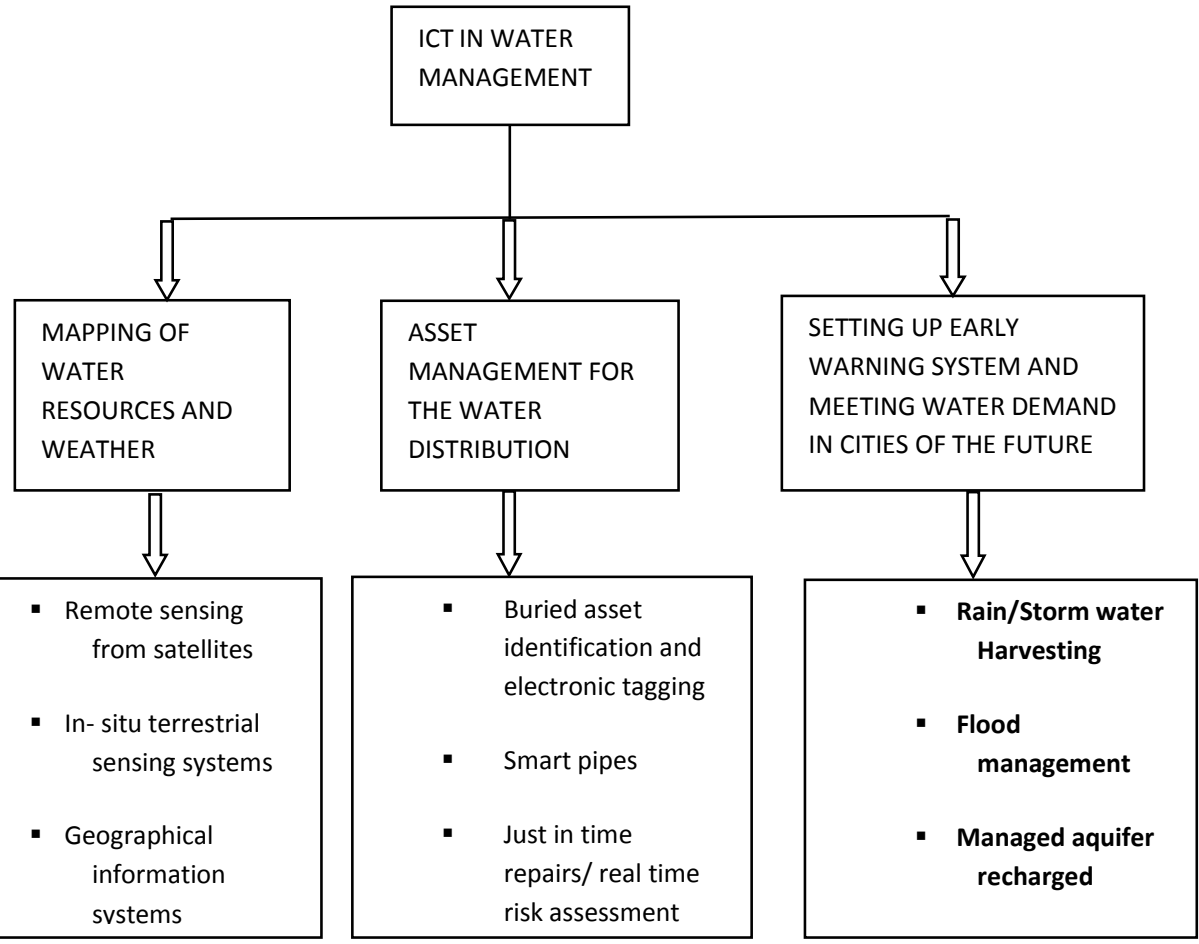




\section{International Journal of Computer Applications Technology and Research}

\section{Volume 6-Issue 3, 121-129, 2017, ISSN:-2319-8656}

change in developing countries " International Conference on ICT for Africa 2013, February 20 -23.

[3]http://www.wmo.int/pages/mediacentre/press_relea ses/pr_864_en.html

[4]http://www.itu.int/themes/climate/events/cop16/sg. html

[5] http://www.itu.int/publ/R-HDB-45/en

[6] ITU-T Technology Report, Major Areas for ICT in Water Management available at: http://www.itu.int/oth/T2301000010/en.

[7] Matarira, C.H., Makadho, J.C., MukahananaSangarwe, M 2004. "Vulnerability And Adaptation Of Maize Production To Climate Change In ZIMBABWE", Zimbabwe Government Publication.2004.

[8]The Hyogo Framework for Action 2015.” Building the Resilience of Nations and Communities to Disasters, available at: http://www.unisdr.org/eng/hfa/hfa.htm, 2005-2015

[9] Russell J, Zimbabwe. (2008)." Country At Risk of Climate Change Effects", available at: http://www.zimbio.com/Zimbabwe/articles/263/Zimb abwe+Country+Risk+Climate+ Change Effects.

[10] Mobile cellular subscriptions per 100 inhabitants, 2010 available at: http://www.itu.int/ITUD/ict/statistics/material/graphs/ 2010/Mobile_cellular_00-10.jpg.

[11] IPCC Climate Change, Synthesis Report 2007.. Contribution of Working Groups I, II and III to the Fourth Assessment Report of the Intergovernmental Panel on Climate Change 2007.
[12] ITU/WMO Handbook "Use of Radio Spectrum for Meteorology: Weather satellite, Water and Climate Monitoring and Prediction", available at:http://en.wikipedia.org/wiki/Weather_satellit e.

[13]The Nairobi Framework: http://cdm.unfccc.int/Nairobi_Framework/index .html

[14]'Wireless Sensor Networks for marginal farming in India' by Jacques Panchard, École Polytechnique Fédérale de Lausanne, Switzerland.

http://commonsense.epfl.ch/Resources/thesis.pd f

[15]WMO 'Mobile Systems to Revolutionise African Weather Monitoring www.wmo.int/pages/mediacentre/press_release s/pr_855_en.html

[16] GSMA 'Green Power For Mobile' http://www.gsmworld.com/our- work/mobile planet/green power for mobile/index.htm

[17]http://ourworld.unu.edu/en/how-thingswork-environmental-satellites/

[ 18] ITU-T Technology Report 2010. On "ICT as an Enabler for Smart Water Management (October 2010)". http://www.itu.int/oth/T2301000010. 